\title{
"COMO VAI SER O CORTE?": AS MEMÓRIAS DO BARBEIRO HENRIQUE NO BAIRRO DO COMÉRCIO, BELÉM - PA
}

\author{
Manoel Cláudio Mendes Gonçalves da Rocha ${ }^{1}$ \\ Flávio Leonel Abreu da Silveira ${ }^{2}$
}

\section{Introdução}

Partindo de reflexões acerca da presença do ofício de barbeiro na cidade de Belém, o trabalho em questão visa compreender os processos de sociação ${ }^{3}$ (Simmel, 1983) e de (re)construção de memórias que tomam como palco a barbearia de Seu Henrique, situada no bairro do Comércio, nos arrabaldes da região portuária da capital paraense. Para tanto, o presente estudo toma por referência a trajetória e a experiência profissional do barbeiro, senhor que exerce o ofício desde o ano de 1975.

Através do exercício de rememorar as suas vivências seu Henrique acaba por deslocar-se através dos anos - uma ritmanálise no sentido bachelardiano (Bachelard, 1988) - revelando no fluir de suas narrativas as modificações ocorridas no bairro em que labuta, a partir daí a presença dos atores sociais que experiência(ra)m tal meio praticado (Certeau, 1994), bem como as transformações pelas quais o ofício de barbeiro passou ao longo dos anos vem à tona mediante o caráter reflexivo de suas memórias narradas.

Mediante o método etnográfico de pesquisa de campo o estudo realizou-se por meio de observação participante e manutenção de diário de campo (Malinowski, 1980; Foote-Whyte, 1980), auxiliado pelo uso de registro fotográfico, visando a composição de narrativas etnográficas de caráter imagético (Rocha; Eckert, 2003). Por meio de visitas continuadas à barbearia foi possível apreciar as formas de sociabilidade (Simmel, 1983) encenadas no lugar, o intercâmbio de experiências (Benjamin, 1985) entre os sujeitos que ali se encontram e realizar entrevistas abertas com o barbeiro, registradas em diário de campo e, quando possível, com o auxílio de gravador digital. Inspirada na figura do flâneur (Benjamin, 1989), a prática de caminhadas sistemáticas pelos arredores da barbearia possibilita ao antropólogo aventurar-se pelos itinerários urbanos

\footnotetext{
${ }^{1}$ Universidade Federal do Pará, Brasil.

${ }^{2}$ Universidade Federal do Pará, Brasil.

${ }^{3}$ Não são apenas as diferentes formas de manifestação de sociabilidade que possuem caráter processual, como também estão em constante mudança as próprias motivações e os aspectos mais interiorizados dos indivíduos que os impulsionam à interação social, tendo em vista a dinâmica complexa das relações sociais engendrada no mundo urbano contemporâneo. Tal debate será melhor abordado nos próximos tópicos.
} 
(Certeau, 1994), além de contribuir para uma maior compreensão das memórias narradas por Seu Henrique sobre o lugar a partir da observação do contexto que ancoram as imagens evocadas em suas narrativas.

Contudo, é interessante problematizar a metáfora do flâneur na medida em que a efígie baudeleiriana presente nas reflexões de Walter Benjamin (1989), encenava suas deambulações em metrópoles europeias do século XIX onde a própria ideia de urbano difere significativamente quando o que está em questão é a capital paraense, na medida em que Belém é atravessada por uma gama de saberes e fazeres que evocam a dimensão do rural em pleno espaço urbano (destaque-se o rural presentes nas imagens da beira do rio, que está diretamente associado à existência de relações entre humanos e nãohumanos intermediadas pelas águas). Logo a presença de imaginários diversos está tensionada por visões racionalistas, pragmáticas e de um progresso urbanístico que constituem a experiência no mundo urbano contemporâneo.

Deste modo, a proposta das errâncias urbanas (Jacques, 2006), permite refletir de forma crítica sobre a prática etnográfica inspirada na metáfora do flâneur e emerge como alternativa metodológica nesta pesquisa, na medida em que através do "errar" pela cidade e perder-se por entre as suas figurações, memórias e símbolos, o etnógrafo tem a possibilidade atenuada do "estranhamento", na medida em que busca "reencontrar-se", desprendendo-se da observação focada no aspecto visual, e permitindo-se perceber e experienciar a urbe através dos outros sentidos. Em outros termos, é preciso pensar as dinâmicas do trabalho de campo não apenas como observação científica, mas como fazer antropológico que se funda na ação e no apropriar-se do espaço urbano através do caminhar, compreendendo a esfera afetiva e criativa da experiência etnográfica.

De acordo com os estudos de Fukelman e Lima (2008) as barbearias foram assumindo destaque ao longo dos séculos XVIII e XIX, constituindo-se como espaços onde se desenrolavam uma série de práticas sociais no espaço urbano. A barbearia, lugar onde prevalece o público masculino, deixa de ser apenas o local de trabalho de barbeiros a partir do momento em que passa a reunir sujeitos de diversos grupos sociais, sendo palco de processos de sociação diversos, mas acima de tudo de sociabilidade (Simmel, 1983), onde se encenaria a vida vivida (Certeau, 1994):

A própria barbearia, ambiente predominantemente masculino, ganha um papel social relevante: ponto de encontro de novidades, onde se trocam informações sobre o acontecido, vida alheia, notícias locais. (Fukelman; Lima. 2008). 
Em oposição ao pensamento comum de que os barbeiros, assim como profissionais que exercem outros "ofícios tradicionais" (sapateiros, alfaiates, costureiras), estariam "perdidos no tempo" ou mesmo "fadados ao desaparecimento", caminhando rumo à poeira do esquecimento, os dados aqui apontados, demonstram que tais atores sociais continuam exercendo suas atividades em meio à dinâmica de práticas sociais no mundo urbano belemense. Estudos recentes sobre a presença de tais profissionais no distrito de Icoaraci $^{4}$ (Silveira; Soares, 2007) acrescentam evidências para tal afirmação, na medida em que:

"[...] os conhecimentos e técnicas relativos ao ofício de barbeiro estão ligados a diferentes aspectos do mundo urbano em Icoaraci, uma vez que aproximam práticas laborais a processos de sociabilidade em consonância aos modos de vida dos freqüentadores da barbearia" (Silveira; Soares, 2007).

Através de sua profissão os barbeiros assumem papel social de destaque no contexto do bairro onde o seu estabelecimento se localiza, tendo em vista que ao longo de suas trajetórias de vida acabam por acumular experiências e lembranças acerca dos processos de transformação e de modificação das paisagens citadinas, resultando em uma série de memórias, sejam elas individuais ou coletivas, que são frutos de processos de interação com os sujeitos que frequentam/frequentaram a barbearia - indivíduos dos mais diversos grupos sociais, intercambiando as mais diferentes experiências de vida na urbe.

\footnotetext{
A barbearia é, então, o espaço onde tais fenômenos emergem como elementos importantes nas interações do senhor com o público que busca seus serviços. Isso porque, diante do jogo intersubjetivo vivido na relação proximidade-distância entre o barbeiro e seus clientes é que acontecem as manifestações formais do processo de sociação (...) no meio urbano belemense. (Silveira; Soares, 2007).
}

Por meio de sua atividade profissional e pela dinâmica que tal prática engendra no mundo urbano belemense, estes "guardiões da memória" (Benjamin, 1985) contribuem para a (re)construção da história das transformações da cidade de Belém, para além daquela que consta nos documentos oficiais, porque referida àquela que anda de "boca em boca" (Benjamin, 1985), por meio do intercâmbio de experiências característico das artes de narrar (Benjamin, 1985).

\footnotetext{
${ }^{4}$ Distrito que faz parte da Região Metropolitana de Belém.
} 
Neste sentido, as narrativas do barbeiro Henrique fornecem pistas para compreendermos como a cidade de Belém, uma das metrópoles da Amazônia que vive os anseios de modernizar-se (diríamos que mais intensamente desde a segunda metade do XIX até o contemporâneo), uma avidez por "desenvolvimento" e "progresso", que, todavia, preserva ao mesmo tempo, um tipo de atividade ${ }^{5}$ que podemos considerar como "tradicional" 6 . Em outros termos, podemos interpretar as tensões entre este desejo pelo novo como uma convivência com o "antigo", ambos figurando como aspectos dinamizadores do mundo urbano belemense.

\section{O bairro e a barbearia: mudanças ao longo do tempo}

Trilhando caminhos errantes pelo bairro da Campina e do Comércio, lançando passos pelas calçadas tortuosas da Rua Gaspar Viana - com suas falhas e seus buracos no calçamento, com o cheiro forte de amônia aos pés dos postes de luz e o lixo que se acumula em algumas de suas esquinas, impedindo a passagem dos pedestres naquele passeio estreito, nos deparamos com um renque de construções antigas, algumas delas passando por visível processo de arruinamento, sendo que outras assumem o lugar de moradia de famílias. Há ainda aquelas que servem a vários tipos de atividades. É dentre estes lugares que se encontra a barbearia de Seu Henrique, que trabalha como barbeiro naquela rua desde o ano de 1975 - exercendo por volta de vinte anos o seu ofício no lugar onde até hoje está localizado o seu negócio.

\footnotetext{
${ }^{5}$ Aqui privilegiamos o ofício de barbeiro, mas outros trabalhos apontam uma variedade de atividades que podem ser caracterizadas da mesma forma, tais como o ofício de sapateiro (Rocha, 2011), de alfaiate, de costureira, como vem indicando as pesquisas realizadas no âmbito do projeto intitulado "Paisagens, memória coletiva e trajetórias sociais. Estudo antropológico de fronteiras culturais no mundo urbano contemporâneo na cidade de Belém - Pará", coordenado pelo Dr. Flávio Silveira.

${ }^{6}$ Caracterizamos aqui os ofícios como um trabalho "tradicional", tendo em vista a profundidade temporal que estas atividades possuem e por sua permanência no contexto das práticas sociais engendradas na cidade. Esta ideia de permanência não pode ser confundida com uma espécie de "congelamento" no tempo, na medida em que os ofícios, tais como o de barbeiro, estão em devir e, por isso, sujeitos as vicissitudes do tempo. Pensar o ofício a partir desta perspectiva permite também colocar em questão as tensões entre as noções de tradição e de modernidade tão peculiares à prática etnográfica no mundo urbano belemense, possivelmente presentes em outras metrópoles brasileiras, mas que assumem destaque acentuado na capital paraense.
} 

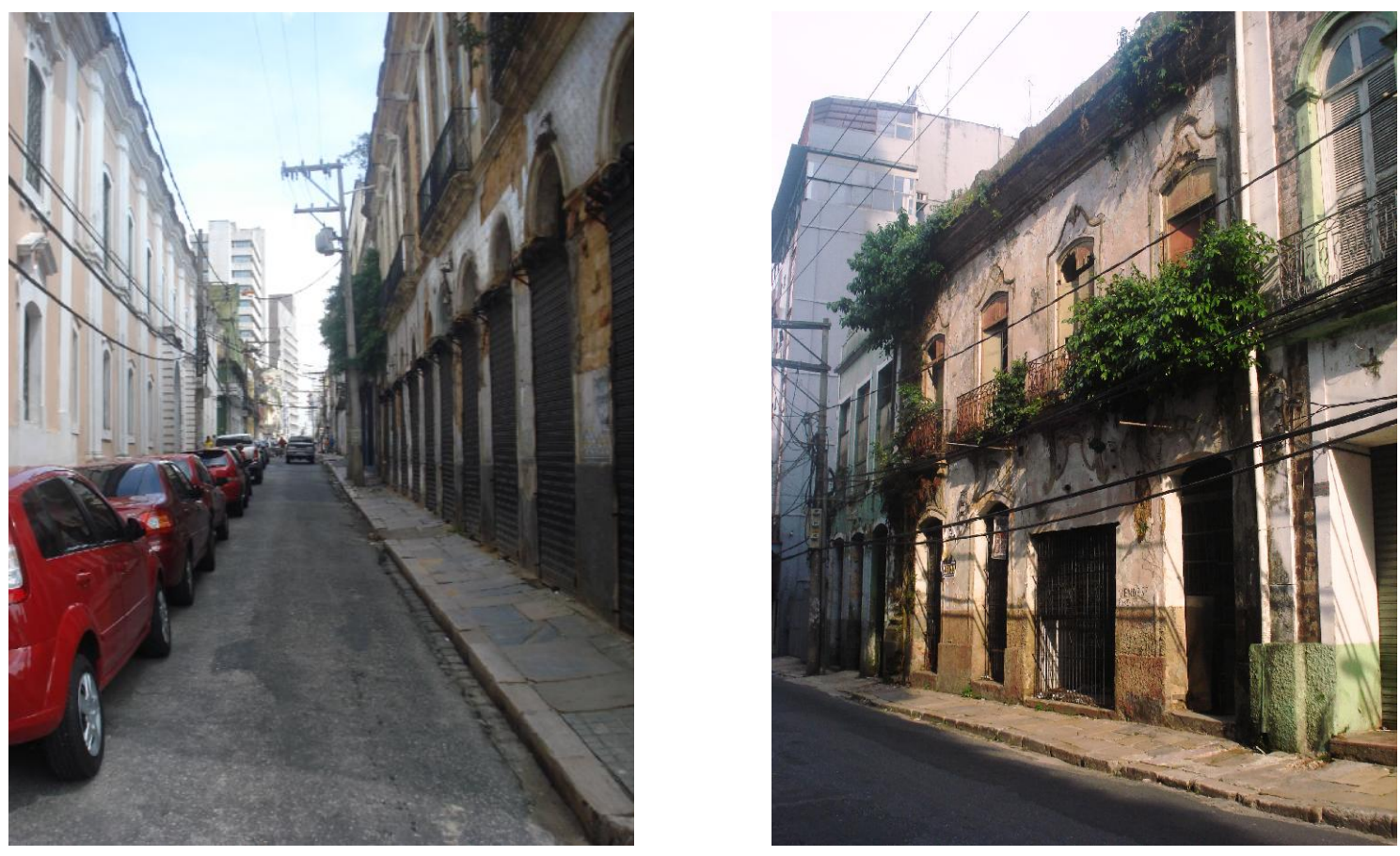

A barbearia fica em uma pequena sala de um prédio em processo de arruinamento, que faz parte de um conjunto de casarões e edifícios derruídos que ficam nas proximidades do estabelecimento. Ao longo de seis meses ${ }^{7}$, foram realizadas visitas continuadas ao espaço de trabalho de Seu Henrique, através das quais foi possível conhecer uma parte da história de vida daquele senhor e, a partir desta, a própria história do lugar. Em suas narrativas, o senhor contou sobre como havia se tornado barbeiro e de como conseguiu aquele espaço para instalar o seu estabelecimento comercial:

Eu sou maracanaense [oriundo da cidade de Maracanã, situada na região do Salgado Paraense]. E lá em Maracanã eu aprendi a cortar cabelo, e lá mesmo eu trabalhei, tinha uma barbeariazinha... E cortava cabelo lá. Depois, tive que vir pra cá pra Belém me apresentar na Aeronáutica. E da aeronáutica, quando sai, vim trabalhar em um salão bem aqui... E fiquei por aqui na Gaspar Viana. Quando o salão fechou, vim trabalhar sozinho, mais ali pra frente perto d'O Liberal ${ }^{8}$, e d'O Liberal eu vim pra cá. Que aqui eu tinha os meus clientes da Cooperativa. A diretoria toda cortava cabelo comigo, e me trouxeram pra cá, ficar aqui perto. Inclusive tinha até uma brincadeira do presidente que disse: "fica aqui, porque se tiver chovendo, pelo menos a gente não se molha pra cortar o cabelo". Aí, foi assim que eu vim pra cá. E aqui eu já tô há muito tempo... 20 anos, 22, parece! Nem sei!

A barbearia se localiza no prédio onde antes fora a sede da "Cooperativa" mencionada por Seu Henrique, a SOCIPE (Cooperativa da Indústria Pecuária do Pará Ltda). Hoje em dia o prédio não é mais utilizado pela Cooperativa, pois esta mudou de

\footnotetext{
${ }^{7}$ Durante meados do segundo semestre de 2010 e primeiros meses de 2011, no contexto das pesquisas referentes ao projeto supracitado.

${ }^{8}$ Ali funcionava a tipografia do Jornal O Liberal, um dos principais veículos de informação em Belém e no estado. Sobre este prédio falaremos mais adiante.
}

Iluminuras, Porto Alegre, v. 14, n. 34, p. 231-252, ago./dez. 2013 
endereço, funcionando no bairro do Tapanã. Segundo o barbeiro, por conta desta mudança o prédio ficou, de certo modo, "abandonado" e em vias de arruinamento. Estão em uso duas salas do prédio, uma delas onde fica a barbearia de Seu Henrique, e uma segunda que é alugada como depósito para "carrinhos" de venda de camelôs e ambulantes. Desde então, o barbeiro é, em certa medida, o responsável pelo prédio, encaminhando as correspondências e similares para a nova sede da Cooperativa.

O prédio, mesmo que em processo de arruinamento, não deixa de ser o espaço onde se estabelece uma série de práticas sociais. Na barbearia além do corte de cabelo e de barba, as relações entre barbeiro e cliente e entre aqueles que, de modo geral, frequentam o lugar, engendram processos de sociabilidade (Simmel, 1983) - conversas sobre temas variados; contações de histórias risíveis; leitura de jornal e comentários acerca das notícias, por exemplo - e o intercâmbio de experiências entre tais sujeitos (Benjamin, 1985), levando em consideração que esta troca inerente às narrativas contadas é fundamental para o processo de (re)construção das memórias.

Além disso, o prédio em questão é utilizado por alguns trabalhadores que exercem as atividades de camelô e de vendedores ambulantes nas proximidades, dando uma dinâmica outra ao lugar. Como mencionado anteriormente, uma das salas do prédio da Cooperativa é atualmente alugada como depósito.

Próximo à barbearia fica o prédio de um dos principais jornais de Belém, onde anos antes eram impressos de segunda a segunda os exemplares diários de O Liberal. Alguns metros depois, encontra-se o Sindicato dos Estivadores. Nas palavras do barbeiro:

"Ah, mas a Cooperativa, quando tinha aqui, isso aqui era muito movimentado. Tinha O Liberal ali, trabalhavam ali. Tinham os estivadores, era um forte sindicato de estivadores, eram 400 estivadores titulares e 400 suplentes. Eram 800 homens trabalhando nesse porto. E o pessoal da Cooperativa, da Receita Federal e cortava muito cabelo, era muito frequentado, não tinha quase nem tempo pra almoçar".
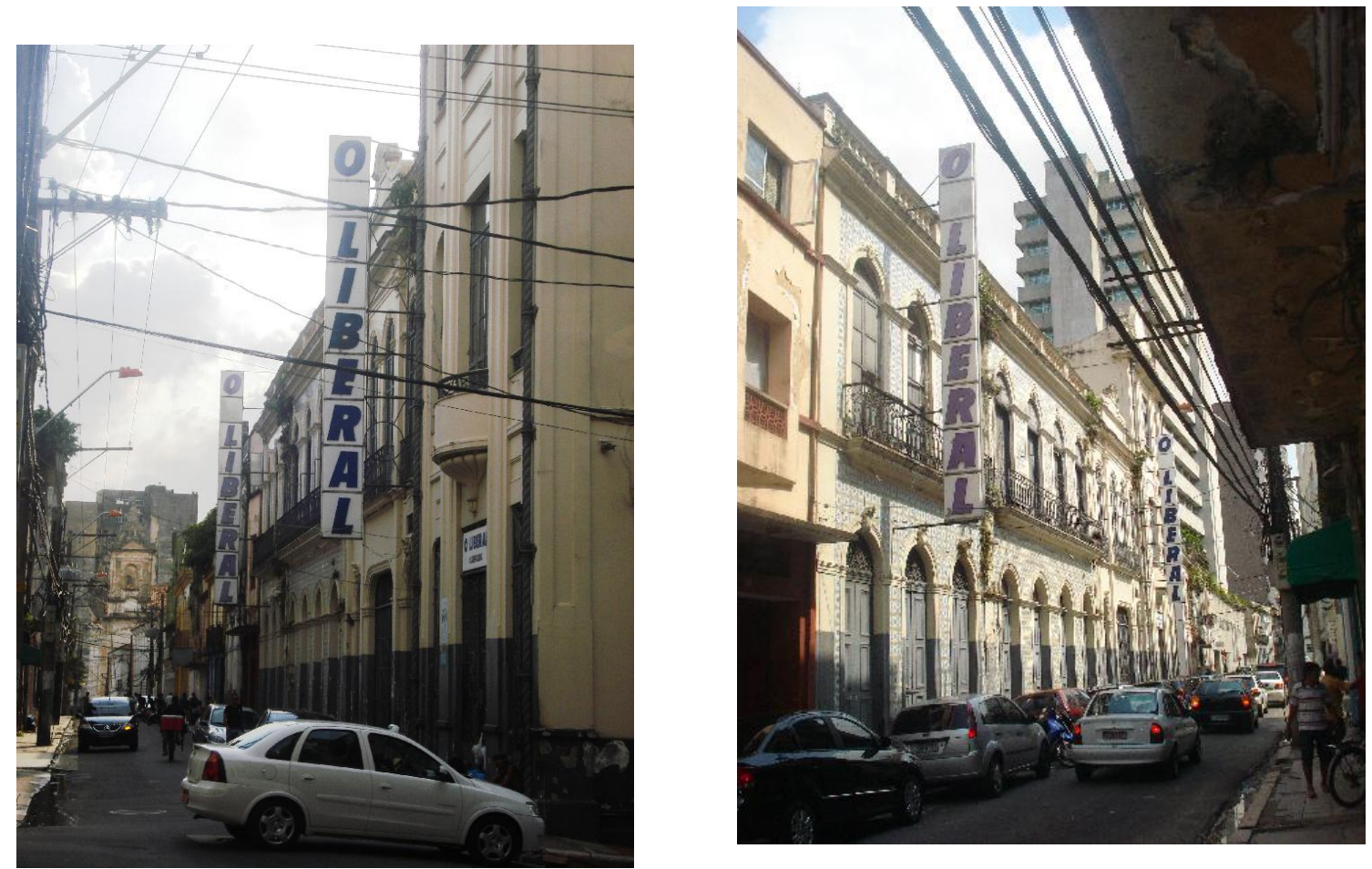

Iluminuras, Porto Alegre, v. 14, n. 34, p. 231-252, ago./dez. 2013 
Certa vez, ao falar a respeito da vizinhança, Seu Henrique comentou que a Gaspar Viana antes "era" uma rua comercial, que já teve "muitos comércios" ali, citando uma série de estabelecimentos que funcionaram no local em outros tempos (o jornal $\mathrm{O}$ Liberal, o Sindicato dos Estivadores, um escritório de advocacia, hotéis que hospedaram "pessoas importantes", dentre outros). Agora, os "comércios" estariam mais próximos às ruas como a João Alfredo e a Santo Antônio, e as pessoas que circulam na Gaspar Viana, agora só "passavam" por ali a caminho das ruas de maior movimento.

Eram estas pessoas, desde funcionários do jornal O Liberal aos estivadores que trabalhavam na região portuária de Belém, como também advogados, promotores, juízes, médicos ${ }^{9}$, dentre outras pessoas ilustres, que frequentavam a barbearia, procurando as habilidades do profissional no manuseio do pente, da tesoura e da navalha. Não apenas lugar do fazer a barba ou o corte de cabelo, a barbearia de Seu Henrique era o espaço onde se encontravam sujeitos oriundos dos mais distintos grupos sociais e que ali intercambiavam diferentes experiências de vida.

Ao longo dos anos, vínculos sociais se construíram e muitos destes se mantêm até os dias de hoje. Como revela Seu Henrique, grande parte de seus antigos clientes continuam frequentando o lugar, procurando pelos serviços do barbeiro, como também por notícias de amigos que há muito não encontram. Foi com entusiasmo, que o senhor comentou que além destes clientes de longa data, a cada dia aparecem novos fregueses, ao que tudo indica, indivíduos que trabalham e/ou transitam cotidianamente nos arredores da barbearia.

Quando compara a Gaspar Viana de "hoje" àquela do passado, Seu Henrique revela, com tom de lamento que a rua "estava ficando pior", mencionando o arruinamento e o abandono de edificações que há pouco tempo exibiam parte do prestígio da cidade $^{10}$; ao mesmo tempo, o barbeiro fala com desânimo a respeito do surgimento de um novo elemento naquele trecho da Gaspar Viana, a presença da prostituição. Aquele perímetro que antes era predominantemente comercial - contando com algumas poucas famílias que ali residiam - agora seria uma zona de meretrício, onde estão localizadas duas boates, sendo uma delas bem ao lado da barbearia. Segundo seu Henrique, as "atividades" das mulheres começam pelo fim da tarde e seguem

\footnotetext{
${ }^{9}$ Profissões que são enaltecidas de prestígio nas narrativas de Seu Henrique.

${ }^{10}$ Parte considerável daqueles prédios e casas foi construída na primeira década do século XX, período da Intendência de Antônio Lemos, revelando os últimos suspiros da economia da borracha no plano de desenvolvimento urbanístico do então Intendente, que pretendia assim, construir uma Belém à imagem de Paris (ROCQUE, 1996).
} 
durante a noite toda, o que na opinião dele estaria associado ao fato de que atualmente a Gaspar Viana ter ficado "muito perigosa" pela parte da noite.

\section{De tesoura e pente na mão: O fazer do barbeiro}

O ofício de barbeiro passou por uma série de mudanças no decorrer do tempo, no que tange ao corpo de atividades que compunham a profissão. Ao longo dos séculos XVIII e XIX estes trabalhadores não apenas barbeavam e cortavam cabelos, como também exerciam as funções de médico, cirurgião e, até mesmo, de dentista, realizando pequenas sangrias e a aplicação de sanguessugas nos enfermos (Grossi, 2004). Foi apenas no século XX que a profissão foi aos poucos se restringindo aos cortes de cabelo e de barba.

Para compreendermos a presença do ofício de barbeiro no mundo urbano contemporâneo (Eckert; Rocha, 2001), mais especificamente o papel que esta atividade representa na cidade de Belém, é fundamental considerar alguns aspectos: as transformações no mundo do trabalho, tendo em vista a inovação tecnológica, a introdução de um instrumental novo na profissão e as novas ferramentas de trabalho; o crescimento da profissão de cabeleireiro e o destaque cada vez maior que estes assumem em relação aos barbeiros neste setor específico no mercado de trabalho (Sá; Teles, 2008); sem esquecer que as tendências e as preferências estéticas mudam ao longo dos anos, resultando no surgimento de novos estilos de cortes de cabelo, bem como a possibilidade de um determinado padrão "ficar fora de moda", o que implica na necessidade de "novas técnicas" voltadas a "novos cortes". Tais fatores implicam diretamente no exercício da profissão, além de alterar o significado do que é ser barbeiro (Sá; Teles, 2008).

A inovação tecnológica acelerada e a consequente introdução continuada de novas ferramentas de trabalho tendem a fomentar mudanças significativas no ofício de barbeiro. Como descrito por Seu Henrique há algumas décadas atrás quando iniciou sua trajetória na profissão, os instrumentos de trabalho utilizados por um barbeiro eram todos "manuais". Segundo as suas ponderações usava-se apenas a tesoura e o pente para o corte de cabelo; para fazer a barba usava-se a navalha devidamente amolada. Contudo, a incorporação das novas ferramentas é inevitável ao exercício da profissão, fato visto com naturalidade pelo barbeiro, pois este acredita que a inclusão deste instrumental 
contribuiu positivamente para o fazer na profissão. As novas tesouras - cada uma com uma função diferenciada - e a introdução de aparelhos elétricos são bem-vindas na perspectiva de Seu Henrique:

“[...] essas máquina elétricas, hoje... que antigamente era manual, a gente cortava com aquela maquina manual, e as tesouras também, umas tesouras hoje são bem afiadas pra cortar o cabelo, tesoura de desfiar, são coisas que realmente... tá aí na... [apontando para a estante onde ficam seus instrumentos] a gente tem que usar".

Isso indica as possíveis vicissitudes às quais estão sujeitos os saberes e os fazeres do ofício de barbeiro, esta profissão tradicional que se encontra imersa nos processos de transformação das práticas sociais encerradas no mundo urbano, este fenômeno que se faz nas tensões entre os impulsos de mudança e os anseios de permanência no devir do tempo (Silveira, 2008). "Há, dessa forma, uma tensão entre o moderno e o tradicional. Todavia, essa é resolvida pelo barbeiro à medida que desenvolve a sua própria 'maneira de fazer"' (Silveira; Soares, 2007).

Fazendo referência à etnografia realizada em Icoaraci (Silveira; Soares, 2007), é possível observar que o barbeiro Seu Jorge - senhor que exerce o ofício no distrito pensa de forma similar a questão dos instrumentos e ferramentas de trabalho:

Seu Jorge deixa claro em sua narrativa a importância de adquirir as ferramentas para a execução das artes de seu ofício. Há uma dimensão operatória vinculada a uma função estética (Leroi-Gourhan, 105:1987), que estão intimamente relacionadas à adequação da forma de suas ferramentas à rítmica das mãos suscitadas pela ação sobre a matéria, no caso os cabelos e a barba. Tais dimensões da ação sobre a matéria visam à produção de formas novas e estetizadas, a partir do processo de liberação da memória pela via do gesto técnico associado à dimensão criativa, dada na elaboração de imagens do Outro. (Silveira; Soares, 2007).

Há estudos que apontam, contudo, uma perspectiva diferente (Sá; Teles, 2008), no qual o grupo de barbeiros estudado não vê com bons olhos a incorporação de novas ferramentas. Tal pesquisa aponta para o fato de que estes velhos barbeiros acreditam que o instrumental ligado à "tradição" é um dos elementos que os identifica enquanto categoria profissional, isto é, as ferramentas "manuais" (tesoura, navalha e pente) são a assinatura do ofício de barbeiros. A inserção de ferramentas elétricas, o uso das giletes descartáveis tomando o lugar da habitual navalha, dentre outras inovações, é para esses senhores o mesmo que destituir a profissão do(s) fazer(es) que a definem como profissão de caráter tradicional (Sá; Teles, 2008). 
Outro fator que tem influência direta na atividade profissional do barbeiro é o crescimento cada vez maior da profissão de cabeleireiro (Sá; Teles, 2008). Na ótica de Seu Henrique, a atividade dos cabeleireiros diferencia-se em muitos aspectos da dos barbeiros: a formação no ofício de barbeiro é transmitida dos mais velhos aos mais novos através da oralidade e da prática, onde o aprendiz necessita de um determinado período de tempo para apreender e acumular tais saberes, aprimorando-se através do fazer próprio da profissão, enquanto que, para ser cabeleireiro, basta instruir-se em cursos técnicos que duram poucos meses para logo em seguida exercer a profissão em salões de beleza.

"É uma coisa ai que... Faz um curso de cabeleireiro ai que, um mês, pô! Ai passa um mês ai já sai cortando cabelo, e vai aprendendo depois. E se ele for um cara inteligente ele aprende por ele mesmo. Não que ele aprende um mês, o cara vai cortar cabelo. A gente, não [referindo-se aos barbeiros], passou muito tempo [para aprender o ofício]. Passava lá olhando, passando a tesoura assim com o pente".

Outro aspecto diz respeito à forma como os cabeleireiros exercem o ofício, que segundo Seu Henrique, distingue-se do trabalho feito pelos barbeiros. Na barbearia se corta cabelo à "moda antiga", com um cuidado e atenção especial com cada cliente, pois o corte não se resume à relação entre o barbeiro e o cliente, traduzindo-se em vínculos de amizade que permanecem ao longo do tempo: o cliente procura a barbearia não apenas para cortar os cabelos, mas para reencontrar velhos amigos - o próprio barbeiro e as outras amizades construídas ao longo dos anos, frequentando o lugar a fim de desfrutar de momentos de sociabilidade entre os conhecidos.

Na perspectiva de Seu Henrique no salão de beleza ocorre o contrário, pois ali se priorizaria a dimensão comercial, a prestação de serviço e a relação de clientela. Conforme o senhor:

"Eu pelo menos, eu aprendi uma profissão que gosto da profissão, trabalho. Corto cabelo porque eu gosto de cortar, e faço com todo carinho e todo cuidado e tal, pra ficar um cabelo bem feito. Hoje nesse salão ai o cara faz rápido, senta lá cara mete a máquina e tal. É como por, é... eles trabalham assim pra, quanto mais eles fizerem mais, trabalhar mais rápido sabe, pra; ganha pelo que faz, tem que fazer mesmo, trabalhar com rapidez. [...] O barbeiro, a gente corta o cabelo de uma maneira diferente. Agora eles [os cabeleireiros] cortam o cabelo colocando o dedo. Pegam o cabelo assim, vão aparando. Nós só cortamo o cabelo à moda antiga, realmente, com o pente e a tesoura, cortando... depois passa a navalha com o pente em cima, pra tirar as pontas, acertando tudo direitinho, diferente. Os cara [cabeleireiros] não fazem isso! Eles nem sabe fazer isso! Chegar lá num salão desse, "depois penteia ai pra mim, como fosse pra tirar as ponta"..."não sei”. Não aprenderam isso, cê tá entendendo?" 
Nestes termos, as imagens evocadas por seu Henrique indicam que:

A mão, pela via complexa do gesto, engendra estéticas que evocam imagens ligadas a uma simbólica singular relacionada ao lugar de pertença dos sujeitos. Nestes termos, a mão cria imagens e símbolos compartilhados pelos grupos no espaço vivido que expressam, através das formas, certas visões de mundo. (Silveira; Soares, 2007).

Além disso, o fazer a barba é uma das atividades exercidas apenas pelos barbeiros - não fazendo parte dos serviços prestados pelo cabeleireiro - e que para Seu Henrique, é o que os identifica como tal:

\footnotetext{
"Ah, a barba. Por isso que a gente chama barbeiro. Porque a gente faz a barba. Esses salão ai, cabeleireiro, eles não faz barba, só cortam cabelo. Aqui não, o cara vem faz a barba. Se quiser talhar a barba, fazer, fazer aquelas barba técnica... Fazer um desenho, como se chama, gente faz, pô!"
}

Elemento diferenciador entre a profissão de cabeleireiro e o ofício de barbeiro, a transmissão dos conhecimentos específicos de cada uma das atividades em questão procede a formas distintas. Enquanto que a primeira requer uma instrução "tecnicizada" (realizada em cursos profissionalizantes e derivados), os saberes e os fazeres característicos do ofício de barbeiro são passados de "mestre" para "aprendiz" por meio da oralidade, da observação e da prática, aprimorando-se ao longo do exercício da profissão: o último escuta atentamente cada ensinamento de seu mentor, observando cada movimento minucioso de suas mãos; a cada novo corte de cabelo e fazer de barba, o principiante aperfeiçoa suas habilidades, adquirindo novas técnicas, harmonizando a destreza das mãos à lâmina da tesoura, ao arranjo do pente, ao corte da navalha, bem como à "modernidade" das "giletes" e as máquinas elétricas.

Neste sentido, as atividades de barbeiro e de cabeleireiro compõem o contraste entre as categorias de "ofício" e de "profissão", observadas por Eliot Freidson (1995). Segundo o autor para as atividades com o grau de profissão a etapa de aprendizado antecede a atividade plena em vias de fato. Existem espaços específicos destinados ao momento de transmissão de conhecimentos - escolas profissionalizantes, universidades, dentre outros - que se localizam do lado de fora da esfera do mercado de trabalho. No universo dos ofícios, contudo, não há cisão entre o espaço de trabalho e o de aprendizado: nas oficinas os mestres e seus aprendizes laboram, instruem, assimilam, isto é, interagem, o que faz do lugar mais do que simplesmente o local da labuta, na 
medida em que se estabelecem vínculos afetivos e laços de pertencimento (Sennett, 2009) a uma categoria de trabalhadores.

Seu Henrique revelou em suas narrativas o seu interesse em ensinar o ofício, para que as próximas gerações deem continuidade à profissão. Ele considera comum pensar que os barbeiros estão "sumindo" ou ficando "esquecidos", porém, acredita que isto não é decorrente de um suposto desinteresse das pessoas por seu trabalho ou que o ofício já "não tem mais lugar" no mundo contemporâneo. Pelo contrário, os serviços destes profissionais são bastante requisitados e eles continuam exercendo suas atividades normalmente, como é o caso de Seu Henrique, que de segunda a sábado tem a barbearia cheia de clientes. Na opinião deste senhor a dificuldade se revela, portanto, em encontrar pessoas dispostas a aprender o ofício de barbeiro e seguir esta profissão.

No cotidiano da barbearia Seu Henrique cria "táticas" (Certeau, 1994) para lidar com as modificações na dinâmica de certas práticas sociais características de Belém, bem como as transformações necessárias no âmbito de sua profissão, no sentido de enfrentar as dificuldades e as vicissitudes que o mundo urbano contemporâneo apresenta. Este senhor (re)inventa o saber-fazer próprio ao ofício de barbeiro, aprimorando o manuseio de seu instrumental de trabalho, incorporando as ferramentas "elétricas" e reelaborando os usos das mais antigas (aquelas "manuais"). Longe de estar "em vias de extinção" o ofício se transforma histórica e culturalmente, especialmente tendo em vista as tensões que permeiam as mudanças na vida cotidiana da cidade, fazendo parte do elenco de expressões culturais que a constituem enquanto meio social praticado (Certeau, 1994).

Ao fazermos uso da categoria simmeliana do conflito social (Simmel, 1983), podemos pensar no ofício de barbeiro como sendo uma atividade, cujos profissionais estão a todo o momento tentando entrar em acordo com o contexto atual do mundo trabalho, quando são impostos continuamente novos padrões e a necessidade constante de "atualizações" nos fazeres. Tal fato implica em processos contínuos de reorganização e de remodelamento da profissão seja pelas inovações na técnica de trabalho, inovações no instrumental e nas ferramentas de trabalho, logo, a elaboração de novas formas sociais (Simmel, 1983). Deste modo, os conflitos inerentes ao mercado de trabalho e esta necessidade de "adaptar-se", que emergem no contexto geral, mas também no interior da própria profissão seriam características não apenas de uma profissão tradicional (que para alguns estaria caminhando rumo às brumas da deslembrança), 
como também de qualquer atividade contemporânea. E assim como mudam os saberes e técnicas que cercam o fazer do barbeiro, modificam-se também as relações entre os sujeitos que freqüentam o lugar, o modo como interagem o barbeiro e seus clientes (incluindo não apenas o caráter comercial da interação, como também sua dimensão sensível). Longe de estar cristalizada, a experiência que estes sujeitos desfrutam na barbearia e os conteúdos mais interiores que os motivam e impulsionam a frequentar/retornar ao espaço transformam-se ao longo do tempo, e as sociabilidades ali manifestadas assumem formas outras.

\section{Os processos de sociação e a (re)construção das memórias}

Através de seu ofício Seu Henrique construiu vários laços não só de clientela, mas também de amizade durante os anos em que vem trabalhando na Rua Gaspar Viana. Muitas dessas amizades resistem ao tempo e persistem até hoje. Entre algumas delas, Seu Henrique comentou sobre figuras importantes na cidade e que já frequentaram a barbearia, tais como Jorge Hage, que já teria sido presidente do Clube do Remo ${ }^{11}$, além de promotores, médicos, procuradores, entre outros. A permanência destes laços é fundamental para a perenidade das lembranças e os vínculos simbólico-afetivos do senhor com as paisagens do bairro, pois a duração de uma memória está ligada a duração do grupo social em que esta é compartilhada, isto é, às circunstâncias que o fazem recordar e, a partir daí, reconstruir ou reconstituir as memórias de seu ofício ligando-as a personagens presentes naquele contexto (Halbwachs, 2006).

Segundo o barbeiro, esse tipo de relação é possível de se construir na barbearia, pelo fato de que nela - diferente, por exemplo, dos inúmeros salões de beleza e seus cabeleireiros - o cliente se sente mais confortável, não vai apenas para cortar o cabelo ou fazer a barba, pois também lê o jornal, "bate um papo". Além do fato de que o trabalho do barbeiro junto ao cliente é diverso ao do cabeleireiro: geralmente se desenvolve um hábito entre os primeiros; com o tempo o barbeiro já conhece o tipo de corte que o cliente deseja - o gosto -; daí a preferência pela barbearia. Deste modo, a barbearia acaba por se constituir enquanto verdadeiro espaço de sociabilidade (Simmel, 1983), na medida em que engendra a íntima relação entre a prática profissional e as interações entre o barbeiro e seus clientes.

\footnotetext{
${ }^{11}$ Clube que ocupa lugar de importância no cenário esportivo paraense, tendo um dos times de futebol de maior história do estado do Pará.
} 
"Eu aqui trabalho, meus clientes, eles já sabem como é, eles espero, eles fico esperando, lendo jornal, revista. Batendo papo, ai eles se conhecem também, que eles ficam muito tempo, né. Muitos se conheceram aqui mesmo sentado na cadeira, ou quando vê se encontram. Umas amizades que realmente fizeram-se aqui na cadeira, aqui, esperando."

O que ocorre é que com o passar do tempo constrói-se uma relação de confiança entre cliente e barbeiro, e mesmo entre os próprios clientes. Aqui a confiança (Simmel, 1983) é o elemento que garante a estabilidade das interações vividas na barbearia, além de possibilitar a continuidade destas relações apesar dos muitos anos passados. Nas considerações de Simmel (1983), o "confiar" é uma mistura de conhecimento e de ignorância, é a "expectativa" depositada em uma relação específica que emerge do equilíbrio entre as informações que se tem a respeito deste tipo de interação, e um sentimento de fé ou de crença (na ausência de informações) nas possibilidades de resultado que tal relação pode oferecer.

Nas primeiras vezes em que o cliente visitar a barbearia ele precisará acreditar na competência do barbeiro para ter um corte de cabelo ou de barba que lhe agrade. Posteriormente, passadas as várias vezes em que fez a barba, cortou o cabelo, desfrutou de uma prosa agradável na barbearia, este cliente já "conhece" suficientemente as habilidades de seu barbeiro, que por sua vez também já tem conhecimento suficiente sobre o corte que será solicitado, conhecedor que é das preferências do cliente, sabendo se utilizará mais a "máquina" e menos a tesoura, por exemplo. Muda, portanto, mediante o convívio e o sentido prático do ofício, o balanço entre a expectativa fundada em um tipo de crença e as informações, por assim dizer, concretas, possibilitando que o ato de confiar amplie-se cada vez mais, enquanto o componente que garante às pessoas que frequentam a barbearia a convicção nos laços fundados naquele espaço.

Foram várias às vezes em que encontramos o lugar cheio de clientes sentados aguardando enquanto Seu Henrique cortava o cabelo, ou fazia a barba de alguém, alguns lendo o jornal do dia, comentando as principais manchetes do exemplar, "batendo papo" e "jogando conversa fora", falando sobre suas rotinas familiares ou de trabalho, ou apenas ouvindo e apreciando as conversas sobre futebol, política e, mesmo, sobre a vida naquela rua, no bairro e na própria cidade de Belém.

A barbearia assumiu com o tempo um papel social de destaque, tendo em vista que acabou por ser o espaço onde se encontram pessoas dos mais diferentes grupos 
sociais e que transitam pelas mais diversas províncias de significado (Velho, 1994), compartilhando na barbearia momentos de interação e de sociabilidade (Simmel, 1983). Ali, diversas trajetórias de vida se entrecruzam, nutrindo um rico intercâmbio de experiências entre sujeitos de diferentes idades, classes sociais, religião ou $\operatorname{cor}^{12}$. A barbearia e o ofício exercido por Seu Henrique contribuem de forma singular para a manutenção de vínculos sociais, portanto para os processos de (re)construção da memória coletiva (Halbwachs, 2006).

Refletindo acerca da noção simmeliana de sociação (Simmel, 1983), que consiste naquilo que impulsiona os indivíduos, motivando-os a interagir e a relacionar-se entre si, podemos pensar que as sociabilidades engendradas na barbearia ao colocarem em jogo os afetos e as afinidades, os desacordos os conflitos, dinamiza os conteúdos das interações entre as pessoas que ali se encontram. Em outros termos, não são apenas as formas como se manifestam as sociabilidades na barbearia que estão se transformando, como também as próprias pessoas e as motivações que as levam a frequentar o espaço e a retornar sempre que possível. Nesse sentido, a própria ideia de sociação pode ser pensada em seu caráter processual.

Percorrendo as pistas do pensamento de Gilberto Velho (1994) acerca do potencial de metamorfose dos indivíduos dos grandes centros urbanos, podemos pensar que ao nos lançarmos às experiências de vivenciar a cidade, trilhando diferentes trajetórias, somos levados a fazer uma série de escolhas permeadas pelas vicissitudes, de acordo com as possibilidades que se apresentam.

Nestas decisões entram em jogo nossas motivações mais interiores, os conteúdos que nos impulsionam a interagir coletivamente. Sendo assim, o que se pretende propor aqui é que não é apenas a forma como barbeiro e o cliente se relacionam que é negociada constantemente, para além disso, são avaliadas e contrabalanceadas as causas, as necessidades, os estímulos, os sentimentos e as intuições que fazem o cliente retornar a barbearia, bem como as que fazem com que o barbeiro ofereça um serviço diferenciado e mais atencioso a determinado cliente, conquistando a sua confiança. $\mathrm{O}$ relacionar-se com o outro na barbearia é dinamizado através do processo criativo engendrado nas manifestações de sociabilidade, nutridas pelas experiências e memórias

\footnotetext{
${ }^{12}$ Não incluí aqui a diversidade de gênero, tendo em vista que a barbearia constituiu-se historicamente como um espaço freqüentado predominantemente por homens, tratando-se de um local marcadamente heterossexual.
} 
evocadas pelas narrativas dos que frequentam o lugar, lembranças que são reinventadas e reelaboradas no exercício do rememorar em grupo.

O barbeiro Henrique, como dito antes, veio de uma cidade do interior, Maracanã. Em Belém, devido ao serviço militar obrigatório, trouxe consigo as suas experiências de vida da cidade natal - dentre estas os saberes e fazeres relativos ao ofício de barbeiro e os anseios de uma vida nova na capital. Através de sua trajetória profissional o barbeiro pode "negociar a realidade" frente às exigências e as imposições do mundo urbano belemense, vivenciando as modificações nas paisagens da cidade ao longo do tempo, experiência por meio da qual pôde entrar em contato com as paisagens urbanas e presenciar a emergência do fenômeno da ruína, refletida tanto no decaimento das construções suntuosas quanto na constatação do desaparecimento das formas de sociabilidade de outrora - e o consequente "decaimento moral" com a consequente presença de boates e da prostituição na rua.

As narrativas do barbeiro revelam que o lugar é possuidor de uma dimensão onírica (Bachelard, 1978). Aqui se compreende este caráter onírico, tomando de empréstimo a noção de casa onírica de Gaston Bachelard (1978). Retomando o pensamento do autor: "a casa é o nosso canto do mundo" (Bachelard, 1978: 200). A partir do momento em que deixamos de viver naquela que foi a nossa primeira residência, não importa o número de lugares em que iremos morar dali para frente, em todos eles a ideia que construímos de lar sempre recorrerá às lembranças que remontam à primeira casa. Na casa nova sobrepõem-se imagens de uma casa dos sonhos, que evoca memórias e afetividades que nos ligam à primeira morada, mas ao mesmo tempo estabelecem laços de pertença com o novo lugar.

Foi no Salão Oliveira que Seu Henrique fez as primeiras barbas e os primeiros cortes de cabelo. Quando Seu Oliveira fechou a barbearia para viajar para Manaus, ele dividiu as ferramentas, os acessórios, as poltronas e as penteadeiras entre seus aprendizes, incentivando-os a prosseguirem na profissão: "Foi ficando isso e aquilo, pra um, pra outro, né". Ou seja, o lugar onde Seu Henrique trabalha hoje, guarda elementos que fazem referência ao primeiro salão onde o barbeiro exerceu a profissão. Sem esquecer as memórias presentes em sua fala quando menciona a importância de Oliveira na sua trajetória de vida. 



A experiência de Seu Henrique como barbeiro na capital paraense teve início na década de 70, no Salão Oliveira. Ao deparar-se com as opções que o mundo urbano lhe apresentou e com as condições adaptativas que lhe foram exigidas para viver no mundo urbano, o barbeiro teve que por em prática estratégias para lidar com o "campo de possibilidades" (Velho, 1994) que a cidade lhe ofereceu e a sua trajetória foi se delineando. As suas ações se orientaram por um projeto que corresponde não apenas às escolhas individuais, mas também, as exigências da vida na urbe. As contribuições de Seu Oliveira foram significativas para o barbeiro Henrique, na medida em que somaram novas possibilidades de "negociar o real" (Velho, 1994).

\section{Considerações Finais}

Partindo da experiência de convívio realizada na barbearia de Seu Henrique e das narrativas deste senhor acerca de sua trajetória de vida, percebe-se como o barbeiro se depara com a necessidade de elaborar "táticas" e de (re)inventar seu ofício, um esforço no sentido de lidar com as tensões resultantes das transformações no mundo do trabalho e da própria dinâmica do mundo urbano contemporâneo. Além disso, através da experiência etnográfica foi possível apreciar as sociabilidades engendradas no espaço da barbearia, bem como a manutenção de vínculos sociais entre sujeitos oriundos de 
diferentes grupos sociais e que trazem consigo as mais variadas experiências de vida para aquele lugar.

A barbearia é o palco onde se encenam processos de sociação entre os antigos funcionários do jornal O Liberal, os membros do Sindicato dos Estivadores, pessoas ilustres na cidade, bem como advogados, promotores, juízes, médicos, entre outros. Na medida em que estes laços estabelecidos entre o barbeiro e seus clientes duram ao longo do tempo, duram também as lembranças daquelas pessoas em relação aquele meio praticado, pois o exercício da memória coletiva se faz intenso enquanto permanecem vívidas as interações entre os diferentes sujeitos que compartilham a experiência do rememorar (Halbwachs, 2006) ${ }^{13}$.

Quando evocamos lembranças sobre determinado fato, mesmo que sob diferentes perspectivas, mas através do exercício de rememorar efetivado em uma experiência coletiva, as memórias passam adquirir mais significado e o passado é ativado no presente (Halbwachs, 2006). Para que a memória coletiva venha a emergir como experiência sensível do real é necessário que o exercício de rememorar junto tenha por base um forte quadro de referência (Halbwachs, 2006).

As manifestações de sociabilidade engendradas na barbearia evocam a experiência sensível da memória: o cotidiano da barbearia se vê, portanto, atravessado por imagens de um tempo passado que a todo o momento é acionado na experiência do presente, mas aberto ao futuro. A efígie do barbeiro "tradicional" ressoa no sujeito que hoje exerce o ofício na Rua Gaspar Viana, um senhor que se empenha na tarefa de lidar com uma série de rupturas, retornos e inovações, no seio dos saberes e fazeres característicos de sua profissão.

Seu Henrique trabalha a mais de vinte anos no prédio da "Cooperativa", lugar onde se manifestaram processos de sociação ao longo dos anos, através dos quais ele constituiu laços de amizades profundos que ultrapassam as relações entre barbeiro e clientes no sentido da mera prestação de serviço do primeiro, vínculos sociais que são fundamentais para a construção da memória coletiva (Halbwachs, 2006).

Longe de encerrar conclusões definitivas, as reflexões aqui propostas demonstram as tensões relativas ao lugar de um ofício "tradicional" na dinâmica do mundo urbano

\footnotetext{
${ }^{13}$ Assim que evocamos juntos diversas circunstâncias de que cada um de nós lembramos (e que não são as mesmas, embora relacionadas aos mesmos eventos), conseguimos pensar, nos recordar em comum, os fatos passados assumem importância maior e acreditamos revivê-los com maior intensidade, porque não estamos mais sós ao representá-los para nós. (Halbwachs, 2006)
} 
contemporâneo. Fica evidente, portanto, a necessidade de lançar o olhar antropológico sobre o fenômeno urbano na capital paraense, problematizando a poética que vibra nas transformações dos espaços e nas vicissitudes do tempo e que envolvem as memórias da Belém de ontem e de hoje.

\section{Referências}

BACHELARD, Gaston. A filosofia do não; O novo espírito científico; A poética do espaço. Coleção Os Pensadores. Seleção de textos de José Américo Motta Pessanha. São Paulo: Abril Cultural, 1978.

BACHELARD, G. A dialética da duração. São Paulo: Ática, 1988

BELÉM. O município de Belém - 1906. Relatório apresentado ao Conselho Municipal de Belém. Belém: Archivo da Intendencia Municipal, 1906.

Beltrão, J. F.; VIEIRA JUNIOR, A. O (orgs.). Conheça Belém, co-memore o Pará. Belém: EDUFPA, 2008.

BENJAMIN, W. Magia e técnica, arte e política: ensaios sobre literatura e história da cultura. Obras escolhidas. São Paulo: Brasiliense, 1985.

BENJAMIN, Walter. Charles Baudelaire. Um lírico no auge do capitalismo. Obras escolhidas III. São Paulo: Brasiliense, 1989.

CERTEAU, M. de. A Invenção do Cotidiano. Artes de fazer. Rio de Janeiro: Vozes, 1994.

ECKERT, Cornelia; ROCHA, Ana Luiza Carvalho da. Premissas para o estudo da memória coletiva no mundo urbano contemporâneo sob a ótica dos itinerários de grupos urbanos e suas formas de sociabilidade. Iluminuras: Série do Banco de Imagens e Efeitos Visuais. v. 2, n. 4. Porto Alegre: BIEV, PPGAS/UFRGS, 17f. 2001

FIGUEIREDO, Betânia Gonçalves. Barbeiros e cirurgiões: atuação dos práticos ao longo do século XIX. Hist. cienc. saude-Manguinhos, Rio de Janeiro: v. 6, n. 2, Out. 1999 . Disponível em http://www.scielo.br/scielo.php?script=sci_arttext\&pid=S010459701999000300003\&lng=en\&nrm=iso. Acesso em 30 Nov. 2011. p. 277-291.

FOOTE-WHYTE, W. Treinando a observação participante. In: ZALUAR, A, (org.). Desvendando máscaras sociais. Rio de Janeiro: Francisco Alves, p. 77-86. 1980.

FREIDSON, Eliot. Para uma análise comparada das profissões: A institucionalização do discurso e do conhecimento formais. Trabalho apresentado no $19^{\circ}$ Encontro Anual da ANPOCS em Caxambu, MG, $1995 . \quad$ Disponível em http://www.anpocs.org.br/portal/publicacoes/rbcs_00_31/rbcs31_08.htm Acesso em 15 jun. 2006.

FUKELMAN, Clarisse; LIMA, Patrícia Souza. Ofícios ambulantes. Catálogo do MAO, 2008. $(\mathrm{s} / \mathrm{n})$.

GROSSI, Ramon Fernandes. Dos físicos aos barbeiros: aspectos da profissão médica nas minas setecentistas. In: História \& Perspectivas, Uberlândia: v.30, p. 255-282, 2004. 
HALBWACHS, Maurice. A memória coletiva. São Paulo: Centauro, 2006.

JACQUES, Paola Berenstein. Elogio aos errantes. In: JEUDY, H. P. e JACQUES, P. B. Corpos e cenários urbanos: territórios urbanos e políticas culturais (orgs.). Trad. Rejane Janowit; revisão técnica: Lílian Fessler Vaz. Salvador: EDUFBA. p. 117-139. 2006.

MAFFESOLI, Michel. A conquista do presente: por uma sociologia da vida cotidiana. Tradução de Alípio de Sousa Filho. Natal/RN: Ed. Argos, 2001.

MAGNANI, José Guilherme Cantor. No meio da trama: A antropologia urbana e os desafios da cidade contemporânea. In: Sociologia, Problemas e Práticas, nº 60,. p. 69-80. 2009

MALINOWSKI, B. "Introdução: o assunto, o método e o objetivo desta investigação". In: ZALUAR, A, (org.). Desvendando máscaras sociais. Rio de Janeiro: Francisco Alves,. p. 3961. 1980

NOVAES, S. C. O Uso da Imagem na Antropologia. In: SAMAIN, E (org.). O Fotográfico. São Paulo: Editora Hucitec/Editora SENAC. p. 107-113. 2005.

ROCHA, Ana. L. C. da.; ECKERT, Cornelia. Etnografia de Rua: Estudo de Antropologia Urbana. Iluminuras: Etnografias na Rua. v.4, n.7. 22f. 2003.

ROCHA, Manoel Cláudio Mendes Gonçalves da. Paisagens de ruína e memória coletiva: o fenômeno das ruínas e as memórias de mestres de ofício e antigos moradores da cidade de Belém. 2011. 83 f. Trabalho de Conclusão de Curso (Graduação em Ciências Sociais) Universidade Federal do Pará, Belém, 2011.

ROCQUE, Carlos. Antonio Lemos e sua época: História política do Pará. Belém: Cejup, 1996.

SÁ, Antônio Fernando de Araújo; TELES, Eduardo Lopes. Cabelo, barba e bigode : Memória dos barbeiros em Sergipe (1960-2007). In: Ponta de lança (UFS), v. 2, p. 113-124, 2008.

SENNETT, Richard. O Artifice. Record, 2009.

SILVEIRA, F. L. A. Belém fantástica, Belém da memória. In: Beltrão, J. F.; VIEIRA JUNIOR, A. O (orgs.). Conheça Belém, co-memore o Pará. Belém: EDUFPA, p. 109-116. 2008.

SILVEIRA, Flávio L. A. da. Paisagens Culturais e Trajetórias Sociais. Estudo Antropológico de fronteiras culturais no mundo urbano contemporâneo na cidade de Belém-PA. Projeto de Pesquisa, 2005.

SILVEIRA, Flávio Leonel Abreu da ; SOARES, P. P. de M. A. O ofício de barbeiro em Icoaraci (PA), diálogos com seu Jorge. Iluminuras, v. 17, p. 01-31, 2007.

SILVEIRA, Flávio Leonel Abreu da. CANCELA, Cristina Donza. Paisagem e cultura: dinâmica do patrimônio e da memória na atualidade. Belém: EDUFPA, 2009.

SIMMEL, Georg. A metrópole e a vida mental. In: VELHO, O. G. O Fenômeno Urbano. (org). Rio de Janeiro: Editora Guanabara, p. 11-25. 1987.

SIMMEL, Georg. Georg Simmel: Sociologia. Col. Grandes Cientistas Sociais, vol, 34. Evaristo de Moraes Filho (Org). São Paulo: Ática, 1983. 
VELHO, G. Projeto e Metamorfose: Antropologia das sociedades complexas. Rio de Janeiro, Jorge Zahar Ed., 1994.

ZALUAR, A. (org.). Desvendando máscaras sociais. Rio de Janeiro: Francisco Alves, 1980.

Recebido em: 05/08/2013

Aprovado em: 10/09/2013 